Full length article

\title{
A critical review on recycling of end-of-life carbon fibre/glass fibre reinforced composites waste using pyrolysis towards a circular economy
}

\author{
S.R. Naqvi ${ }^{\mathrm{a}, \mathrm{c}, *}$, H. Mysore Prabhakara ${ }^{\mathrm{a}}$, E.A. Bramer ${ }^{\mathrm{a}}$, W. Dierkes ${ }^{\mathrm{a}, \mathrm{b}}$, R. Akkerman $^{\mathrm{b}}$, G. Brem ${ }^{\mathrm{a}}$

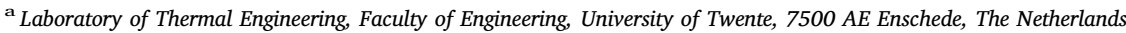 \\ ${ }^{\mathrm{b}}$ Production Technology Group, Faculty of Engineering, University of Twente, 7500 AE Enschede, The Netherlands \\ ${ }^{\mathrm{c}}$ School of Chemical \& Materials Engineering, National University of Sciences \& Technology, 54000, Pakistan
}

\section{A R T I C L E I N F O}

\section{Keywords:}

Carbon fibre

Glass fibre

Reinforced composite

Pyrolysis

End-of-life

Circular economy

\begin{abstract}
A B S T R A C T
The rapid utilization of carbon fibre reinforced composite (CFRC) and glass fibre reinforced composite (GFRC) in main sectors, such as automobile, aerospace, wind turbines, boats and sport parts, has gained much attention because of its high strength, light weight and impressive mechanical properties. Currently, the increasing amount and handling of composite waste at their end-of-life (EoL) has a negative impact on resources conservation and the environment. Pyrolysis, a two-step process, appeared as most viable process to recover not only valuable materials but also produce fuel and chemicals. However, the testing facilities and optimized operation of composite waste in pyrolysis processes to produce materials with low energy consumption and acceptable mechanical properties are still under development and discussion before commercialization. The aim of this article is to review the studies on CFRC/GFRC recycling via pyrolysis processes and highlight their technical challenges and re-use possibilities in high performance composites. The forthcoming commercialization challenges and respective market potential to recyclates using the pyrolysis process will be addressed. This study will also introduce the strong connection between recycling and re-usability of fibres which would help to explain the concept of circular economy and cradle-to-cradle approach. Finally, based on updated studies and critical analysis, research gaps in the recycling treatments of fibrous composite waste using pyrolysis processes are discussed with recommendations.
\end{abstract}

\section{Introduction}

\subsection{Circular economy and global challenges}

The developed industrial countries are generating a considerable amount of polymeric waste (Bhadra et al., 2017; Yazdanbakhsh et al., 2018; Holgersson et al., 2017; Das and Tiwari, 2018). The resources are depleted through a conventional process of materials which results in economic loss (Naqvi et al., 2018). The circular economy brought an emerging concept which restores and regenerates the material by an efficient design (Zhong and Pearce, 2018). This concept aims to protect products and materials at their highest effective utility while minimising negative impacts (Akanbi et al., 2018). In a sustainable society, the recovery of materials and energy by following circular economy is a challenging task (Kirchherr et al., 2017), (Hoogmartens et al., 2018).

Among polymeric wastes, fibre-reinforced composite (FRC) materials have huge world-wide production and consumption because of their utilization in various fields such as construction, aeronautics, aviation industry, oil and gas, sporting goods, wind industry (Lefeuvre et al., 2017) and (Erden and Ho, 2017). FRC materials have a high strength, a high durability, low weight and a high flexibility in shapes making them interesting as alternative to steel and other materials. The growth in the FRC industry not only increased its production and consumption but will also lead to a high amount of end-of-life (EoL) materials. The conservation and recycling of end-of-life scrap FRC has become an important challenge for a sustainable circular economy.

Modern FRC materials originated in the early 1950s with the utilization of carbon fibre, glass fibre which has polyester matrix resin as its constituents. They are widely used in the manufacturing of boats, early cars and water tanks. Following are the core examples of composite application such as, wind energy (Fig. 1a), marine application (Fig. 1b), automotive part (Fig. 1c), biomedical applications (Fig. 1d) (Erden and Ho, 2017).

As an example, the forecast for the fibre reinforced composite materials market in the US for different application segments is depicted in Fig. 2. The market grew by $6.3 \%$ to reach value of $\$ 8.2$ billion in 2014 from the previous years. Economic indicators and market dynamics suggested that composite material will grow much faster and

\footnotetext{
* Corresponding author at: Laboratory of Thermal Engineering, Faculty of Engineering, University of Twente, 7500 AE Enschede, The Netherlands.

E-mail address: s.r.naqvi@utwente.nl (S.R. Naqvi).
} 


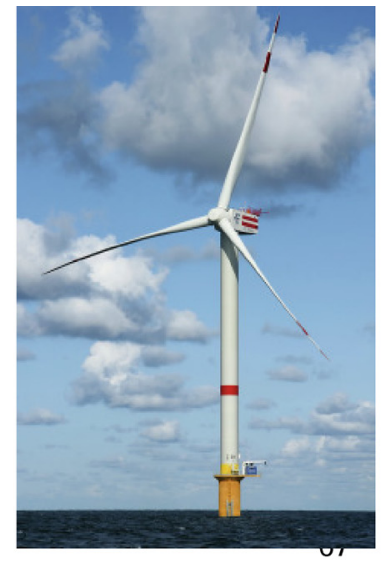

(a)

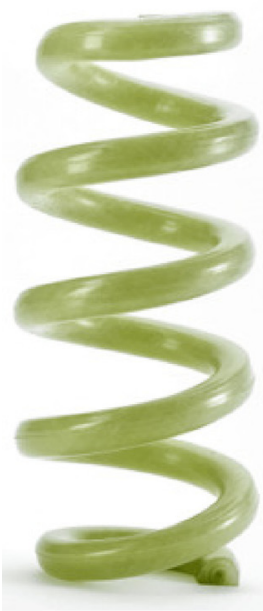

(c)

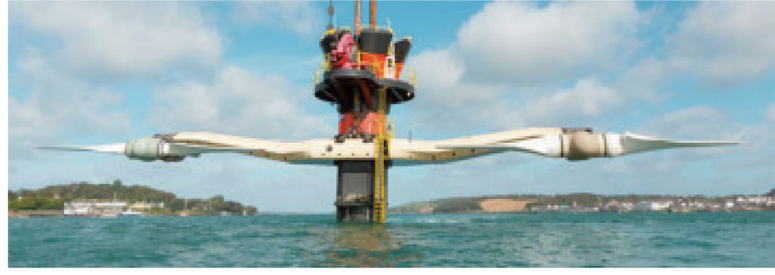

(b)

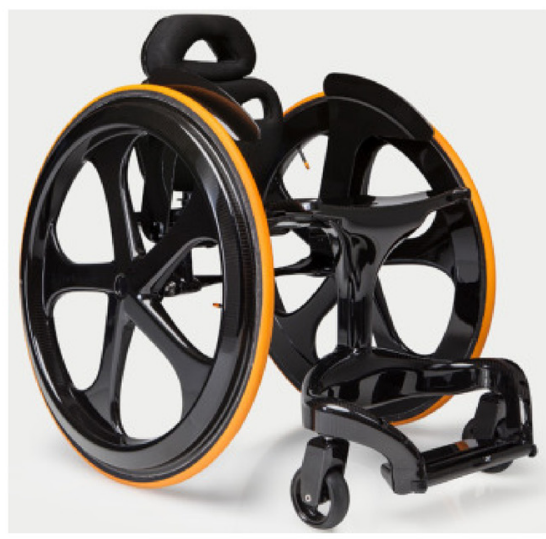

(d)

Fig. 1. FRC composite application, (a) Wind turbine, (b) tidal energy sector, (c) coil spring manufactured by Audi, (d) wheelchair (Erden and Ho, 2017).

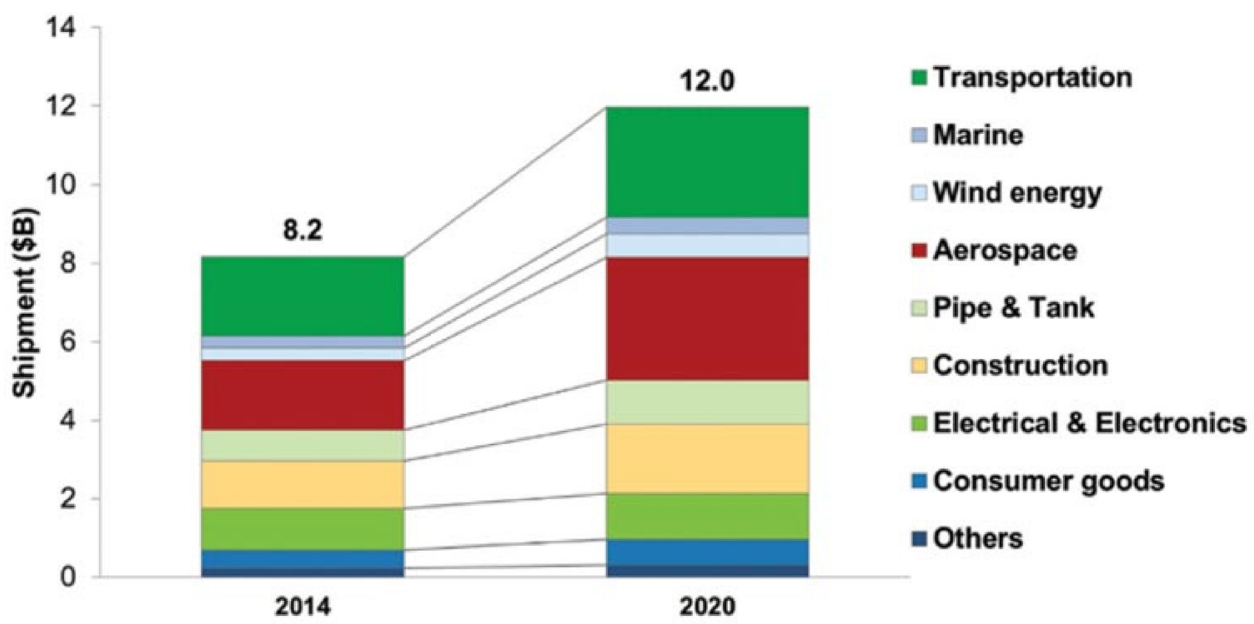

Fig. 2. US FRC market forecast by application segment.

dominating materials are carbon fibres, glass fibres in the reinforcement segment and polyester resin in the resin segment. By 2020, this composite materials market is expected to touch $\$ 12$ billion with a compound annual growth rate of $6.6 \%$ majorly in aerospace, transportation, construction, wind energy and electrical \& electronic industries.
However, currently the handling and recycling of the FRC materials (carbon fibre reinforced composite, CFRC/glass fibre reinforced composite, GFRC) by meeting environmental limitations, governmental legislation, production cost, management of resources and economic opportunity are vital global challenges. It is well understood that turning these composite wastes into a valuable resource and closing the 


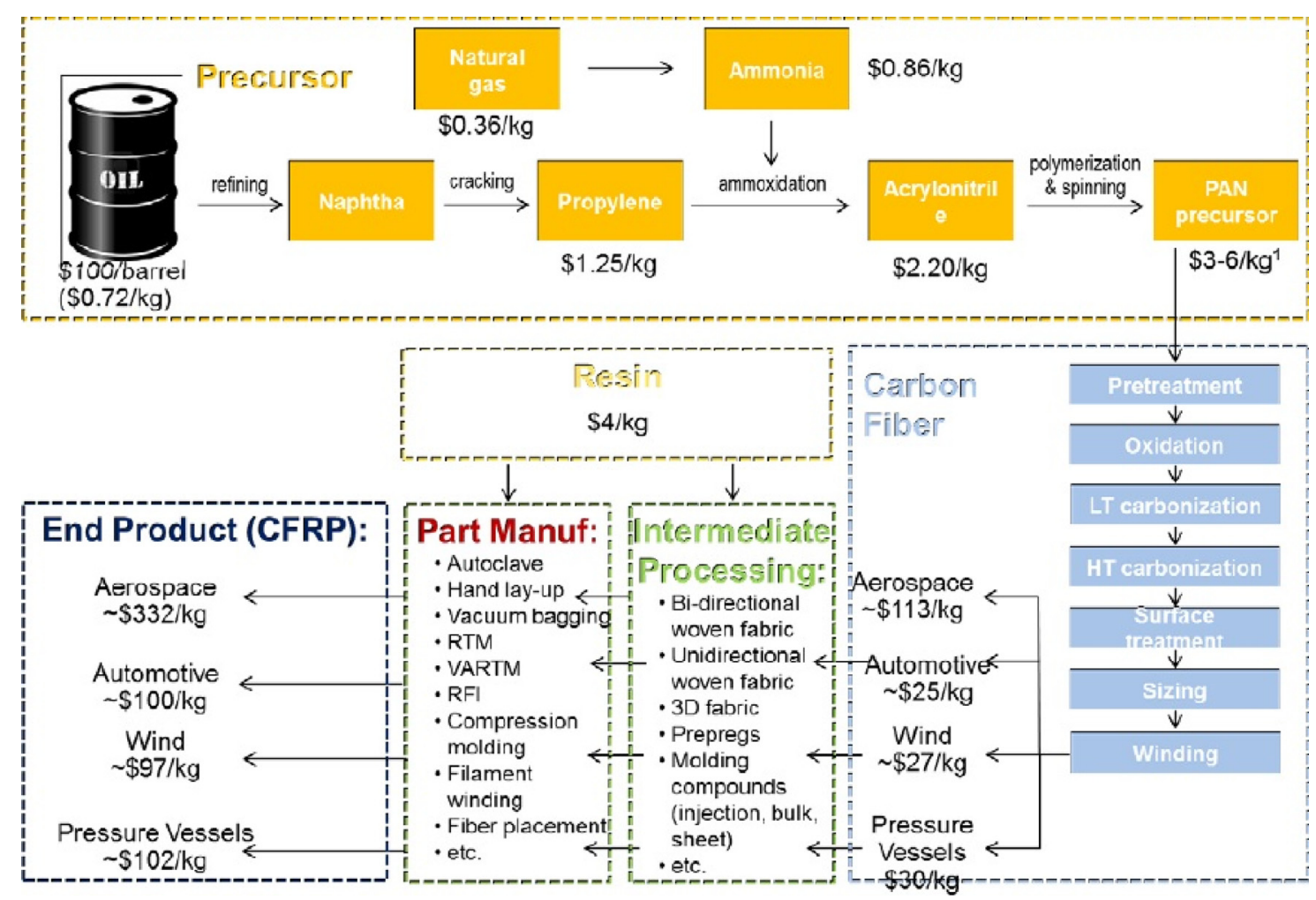

Fig. 3. $\mathrm{CF}$ and CFRC value chain.

loop in the cradle-to-cradle approach is essential for the continuous use of material in a circular economy. To address this issue, a technology readiness level and waste management hierarchy based on review of recycling strategies was presented (Rybicka et al., 2016). Another study described the solution of composite recycling through engineering optimization techniques (Liu et al., 2017). These studies categorically pointed out the impact of pyrolysis process as an emerging and viable technique for composite recycling. Therefore, this study will contribute in systematising the technological knowledge of CFRC/GFRC recycling technique such as pyrolysis process.

\subsection{Carbon fibre and reinforced composite production}

Carbon fibres (CF) are valuable and primarily used as reinforcing agents in high performance composites with thermoset or thermoplastic resins. CF manufacturing is energy intensive but it provides high strength \& stiffness to the composite material by maintain fibre alignment and structural loads (Oliveux et al., 2015). CF compete with glass fibres (GF) in high-performance polymeric composite but are significantly more expensive. Fig. 3 depicts the $\mathrm{CF}$ and $\mathrm{CFRC}$ value chain in a crude oil into CF and CFRC pathway through major steps, intermediate products and unit prices approximately (Das and Varughese, 2016). This figure illustrates the production of CF and CFRC from high value PAN precursor to $\mathrm{CF}$ production and high capital investment which raised the price of $\mathrm{CF}$.

Forecast and demand of $\mathrm{CF}$ and CFRC for different regions are presented by industrial expert in 2013 in Fig. 4a \& b. Europe showed up as the leading in demand of CF (37\% of global total) and expected to $43 \%$ increase in 2020. CFRC demand follows a similar trend and regional distribution as CF demand. CFRC demand in North America and Europe have been estimated $40 \%$ and $36.8 \%$, respectively.

Another important factor relating carbon fibre composite recycling is the projection of market sizes of composites the waste estimation. Pickering 2016 shows the graph of carbon fibre reinforced composite demand mass (kilo tonnes) for various industries, where the black spots indicate the projected composite waste (Pickering and Turner, 2014). A production ramp rates for various segments of application was estimated. In 2017, industrial production scrap and end-of-life (EoL) CFRC scraps for short life application especially in wind energy is sharply increased (Fig. 5).

\subsection{Glass fibre and reinforced composite production}

In contrast to $\mathrm{CF}$, glass fibre (GF) composite production is forecasted to reach 1.1 million tons in Europe by year 2016 (Erden and Ho, 2017). According to a recent published report by German association AVK and CCeV (AVK and CCeV 2015) composite market report in 2015, GFRC generated in 1069 million tonnes and 34\% of Europe's production is associated with wind power industry. GFRC identify as the primary materials in wind turbine blades. Based on the installed capacity in year 2000 , GFRC utilization was 50,000 tonnes. In 2010, it sharply increased to 130,000 tonnes and the amount is progressively increasing. This amount attained $12.5 \mathrm{GW}$ (gigawatt) of energy in year 2016 Today, the use of GFRC in wind power blades is around 150,000 tonnes.

\section{Literature review}

In the last ten years, several studies have reported different existing recovery methodologies of carbon fibre/glass fibre thermoset composite materials for potential applications (Oliveux et al., 2015). Mechanical, thermal and chemical recycling technologies were summarized in details and the impact on economic and environmental aspects of the recycling methods were presented. Pickering (2006), Pimenta and Pinho (2011) and Oliveux et al. (2015) presented and discussed the technical comparison and re-use applications of three recycling methodologies extensively. Their findings agreed that the thermochemical treatment is suitable for carbon fibre reinforced composite (CFRC) recycling because of the high value of carbon fibre for its high grade application such as aerospace and structural sectors. In the case of glass fibre reinforced composite (GFRC), mechanical recycling was indicated 


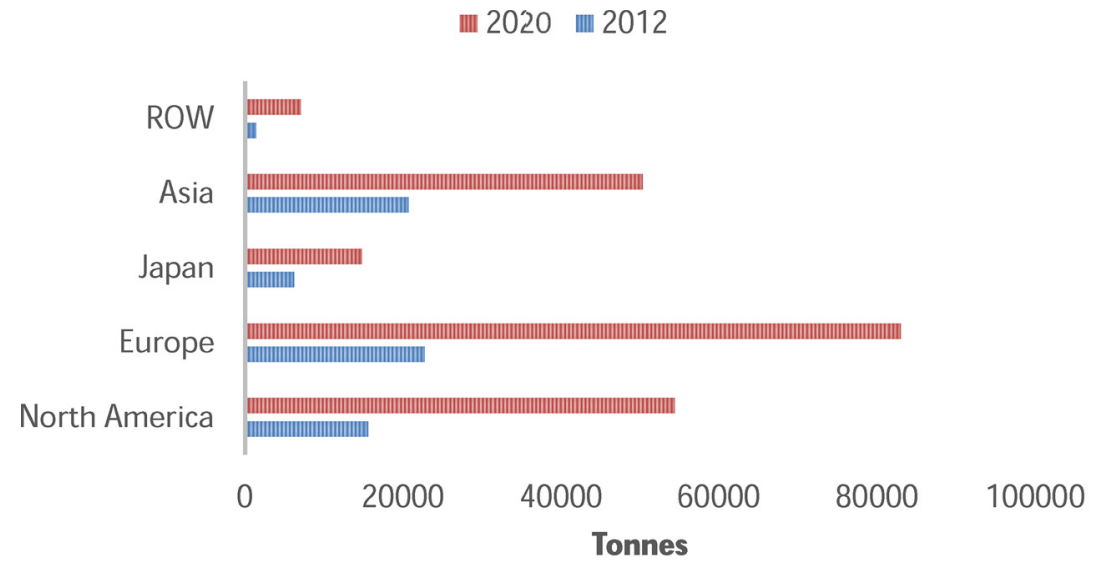

(a)

IIII 2020 ㅍI 2012

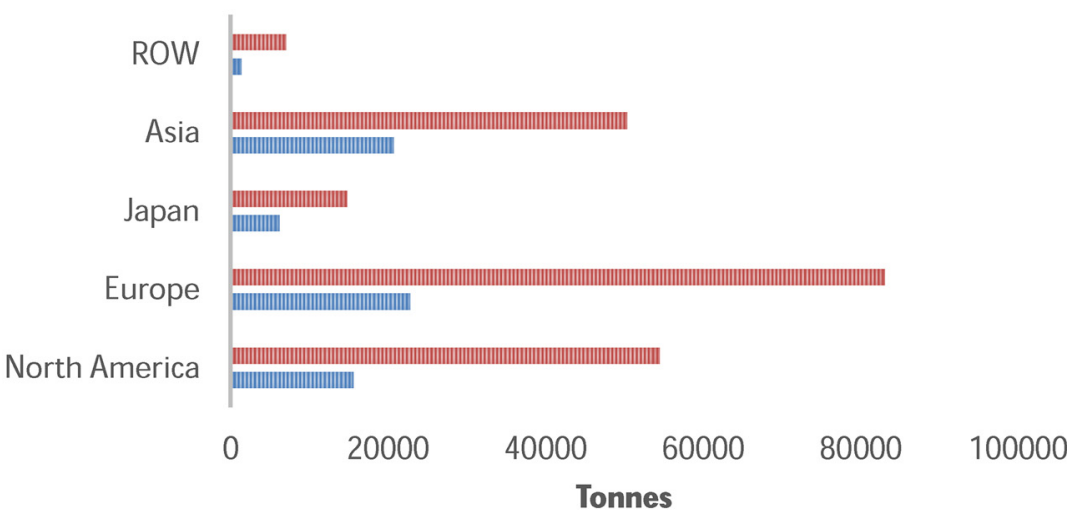

(b)

Fig. 4. (a) CF and (b) CFRC demand (tonnes) by region.

as a better recycling option considering the low price of virgin glass fibre (Oliveux et al., 2015) and (Ribeiro et al., 2015). The energy consumption comparison of mechanical, thermo-chemical (combustion and pyrolysis) and chemical recycling methods were presented by (Wong et al., 2017). According to this study the energy consumption of the pyrolysis process $(30 \mathrm{MJ} / \mathrm{kg})$ is moderate compared to others widely adopted industrial processes. However, the reported methods based on mechanical separation, combustion, gasification or slow pyrolysis in a kiln are either too expensive or produce low quality fibres. Pyrolysis process appeared as the viable and promising method for not only effective recovery but also produce good quality fibres. This study highlights the key pyrolysis process parameters, their effect on fibre properties and re-use of recycled fibre for a new composite. Gaps are identified in current research and possible recommendation is proposed.

Thermo-chemical recycling of fibres involves pyrolysis, low temperature combustion, gasification processes. A low temperature $\left(450^{\circ} \mathrm{C}\right)$ combustion process in a fluidized bed reactor has been developed at the University of Nottingham, UK, for the recycling of CFRCs (Pickering, 2006) and GFRCs (Pickering et al., 2000) and (Zheng et al., 2009). This process recovered fibres and produced clean fuel gas for energy recovery. Fluidized-bed reactors have the capability to treat mixed and contaminated materials. On the other hand, this process required large volumes of high temperature air and resulted in a reduction of fibre properties (especially in case of GF) through mechanical action in the bubbling sand bed. An important question regarding this process is the value of recovered fibres. The intrinsic value of fibre is due to their high cost as virgin material but excessive levels of labour associated with recovery and potentially high level of energy used to a great extent weaken the business case for recycling activities using fluidized-bed low temperature combustion process. A combined process of thermolysis and gasification process for recovery of waste CFRC used in aeronautical industry (López et al., 2013). However, the gasification time was long which led to undesirable alterations in the fibre's surface atomic composition. Pyrolysis processes performed in an inert atmosphere, are the most studied thermal process for recovery of carbon/glass fibres from scrap composite waste (Meyer et al., 2009; Giorgini et al., 2014) (Onwudili et al., 2016). Pyrolysis processes (slow, fast or flash) require optimized process parameters to ensure efficient and maximum recovery of material and fuels \& chemical production (Louwes et al., 2017; Abdou et al., 2016; Habib Al Razi, 2016; Poulikakos et al., 2017). As per author information, there is no comprehensive review of recovery of carbon/glass fibre using pyrolysis process reported yet. The current study not only summarizes the key aspects of pyrolysis process but also highlights the impact of process parameters on materials recovery and fuel production.

\section{Recovery of CF/GF using pyrolysis technology}

For recovery of CFRC/GFRC, the material is heated without the 


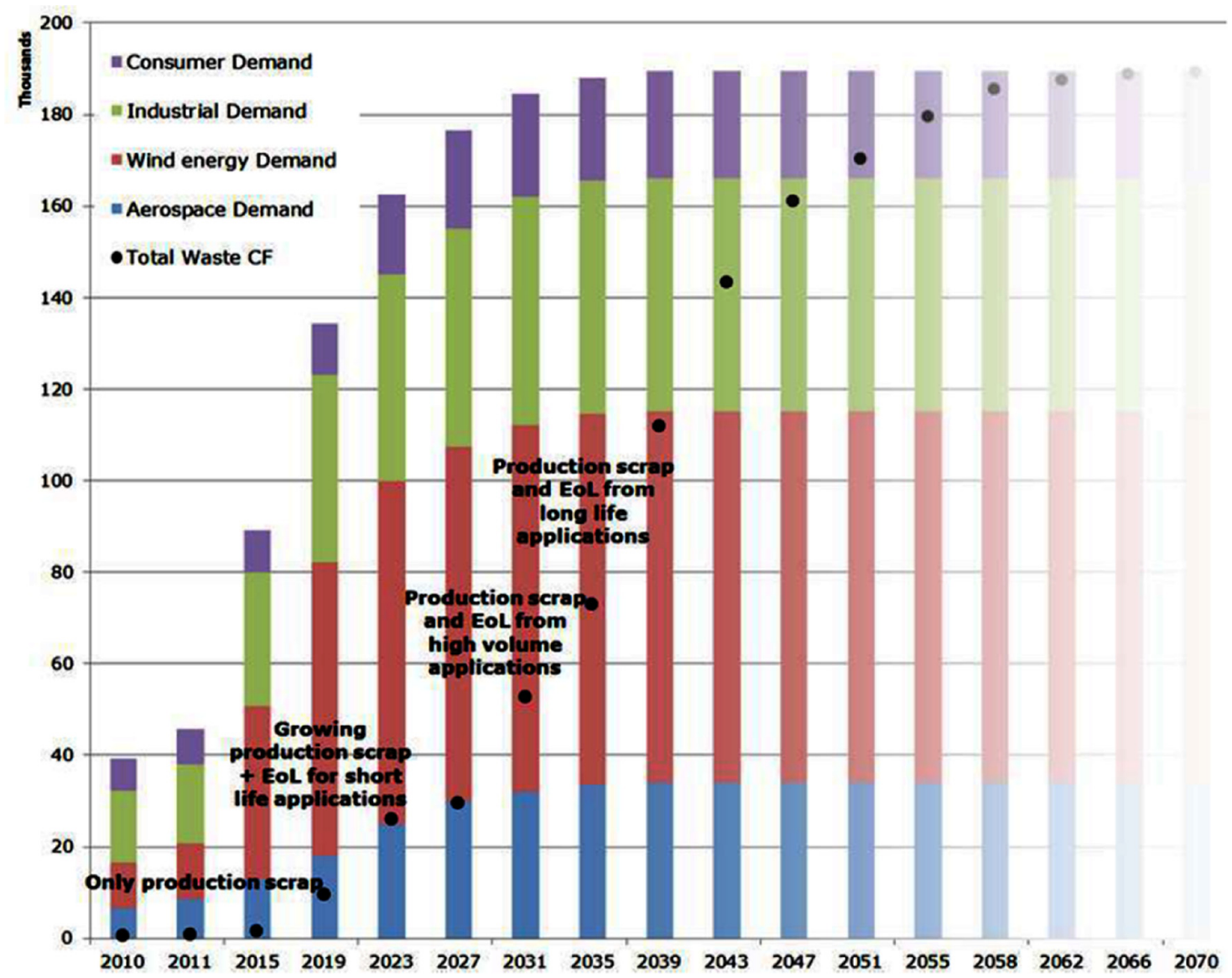

Fig. 5. CF demand in bar and waste in black dot for high value industry (Pickering and Turner, 2014).

presence of oxygen/air, under the inert medium at the temperature range of $350-700{ }^{\circ} \mathrm{C}$ (Meyer et al., 2009; Giorgini et al., 2015; Abdou et al., 2016). The composite matrix decomposes and produces gas, biooil and solids (fibres, fillers and char). The fibre surfaces are contaminated with solid char and a subsequent post-pyrolysis treatment (oxidation using air) is required to burn the char to obtain clean fibres and fillers. This chapter will comprehensive summarize and update the published research articles related to recovery of CFRC and GFRC using pyrolysis process.

\subsection{CF recovery}

Carbon fibre reinforced composite (CFRC) have been utilized increasingly in the aerospace, automotive, wind turbine industry (Vieira et al., 2017) and (Yu et al., 2016). This rapid use has elevated the environmental and economic concerns and raised awareness for recycling the CFRC waste. However, a viable recycling process which could give back fibres and re-manufactured the composite in combination with recycled fibres looks demanding and attractive. Pyrolysis process appeared as most reliable and efficient in terms of energy and material recovery (Witik et al., 2013).

As per author information, Table 1 summarized the studies conducted till now on recycling of CFRC using pyrolysis process. The reactor type, targeted industry, operational conditions of pyrolysis process, post-pyrolysis treatment and pyrolysis product yields are listed and discussed. To reveal the production of components from thermal degradation of carbon reinforced composites, pyrolysis in combination with gas chromatography/mass spectroscopy (Py-GC/MS) was utilized (Bradna and Zima, 1992). However, the pyrolysis mechanism and pyrolysis product yields were not evaluated. To understand the CFRC thermal degradation mechanism in an inert atmosphere, thermogravimetric analysis (TGA) was used to study the influence of temperature on properties of recovered fibres (Meyer et al., 2009). The controlled TGA condition for pyrolysis and post-pyrolysis is possible without harming the fibre properties. To produce activated carbon fibres, CF composite waste is pyrolysed in a fixed-bed reactor at temperatures of $350-700{ }^{\circ} \mathrm{C}$ for $60 \mathrm{~min}$ (Nahil and Williams, 2011). The product yields were determined: solid (70-83.6 wt-\%), oil (14-24.6 wt$\%)$ and gas (0.7-3.8 wt-\%) as a function of temperature. The gas composition showed high concentrations of $\mathrm{H}_{2}, \mathrm{CH}_{4}, \mathrm{CO}$ and $\mathrm{CO}_{2}$ and oil fractions of benzene, toluene, ethyl benzene and phenols. Thus, it can be said that the gas and oil composition produced upon pyrolysis of GFRC and CFRC are similar and displayed similar pattern. The activated fibres upon char oxidation exhibited comparable mechanical properties and could be a raw material for composite industry. Stoeffler et al. (2013) used carbon fibres produced from a pyrolysis in a combination with thermoplastic resin as a representative composite sample for aerospace application. A cured \& uncured carbon fibre/epoxy composite was pyrolysed at $400^{\circ} \mathrm{C}$ using a commercial patented pyrolysis process. The recycled fibres were clean with an average length and diameter of $5.6 \mathrm{~mm}$ and $6.5 \mu \mathrm{m}$. The recovered fibres retained modulus and tensile properties in comparison with the virgin carbon fibre. A new combination of thermolysis (pyrolysis) and gasification (post-pyrolysis) was introduced for recycling of carbon fibre by (López et al., 2013). Pyrolysis was performed in a pilot scale thermolysis/gasification setup at temperature of $500-700{ }^{\circ} \mathrm{C}$ with subsequent gasification at $550{ }^{\circ} \mathrm{C}$ in the presence of air $(12 \mathrm{l} / \mathrm{h})$ for $30-180 \mathrm{~min}$. The produced gas contained higher amounts of $\mathrm{H}_{2}, \mathrm{~N}_{2}, \mathrm{CH}_{4}, \mathrm{CO}, \mathrm{CO}_{2}$, and $\mathrm{C}_{2} \mathrm{H}_{6}$ as the temperature in the thermolysis step increased. However, an optimum residence time in thermoysis before gasification step should be investigated to observe its influence on mechanical properties of the recovered fibres. Giorgini et al. (2015) also used a batch pilot plant for the recovery of CFRC to 


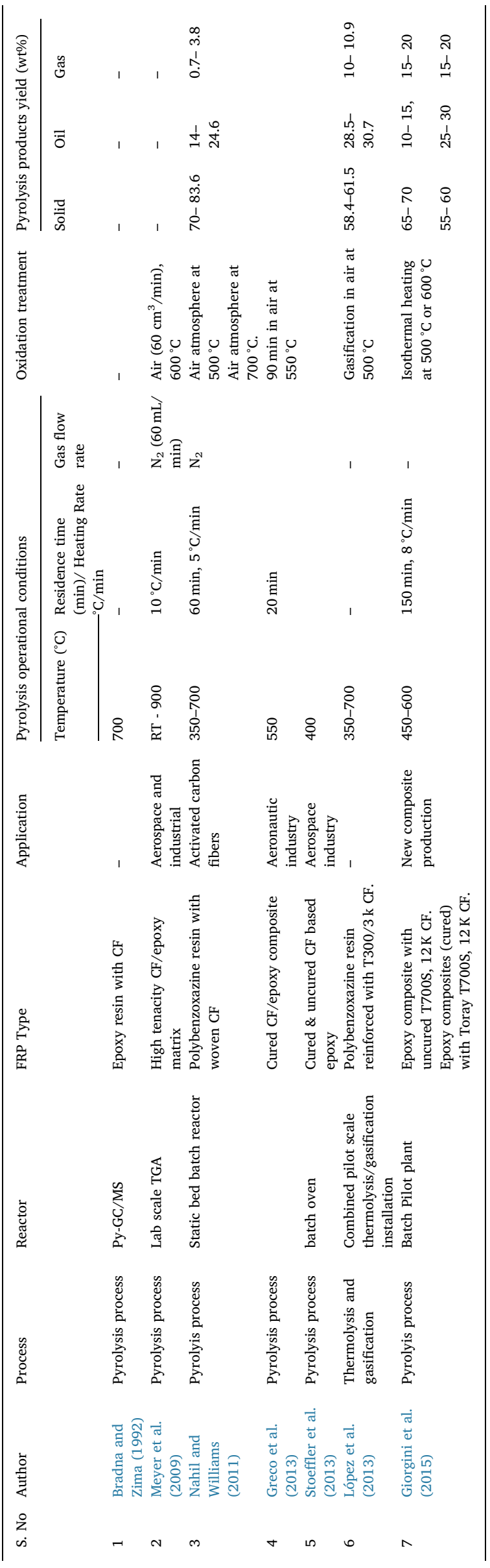

produce new materials with recovered fibres.

The visual inspection of recovered carbon fibres upon pyrolysis was conducted using Scanning electron microscopy (SEM), is presented by (Giorgini et al., 2014, Fig. 6). The author conducted pyrolysis process of prepreg at different temperature $\left(500,550\right.$ and $\left.600^{\circ} \mathrm{C}\right)$ for carbon fibre recovery. Virgin carbon fibres appeared as smooth and homogenous (Giorgini et al., 2015). Carbon fibre obtained from prepreg pyrolysis at various temperatures appear well separated and free from epoxy resin, however, the fibre surface obtained at higher temperature covered with thin layer of pyrolytic carbon. This thin layer consists of residues from the degraded polymers in the case of non-oxidized atmosphere. This residue layer became fragmented or broken in an oxidized atmosphere

This study presents the strong influence of the pyrolysis temperature on products yields and on the surface properties of the composite with recovered fibre. However, the performance of fibre reclaimed at optimized parameters by pyrolysis was not assessed and their mechanical properties in comparison with virgin and new composite was also lacking.

\subsection{GF recovery}

Recycling of GF using a thermo-chemical treatment includes incineration and pyrolysis. This has been subject of previous research however, there is a research gap in understanding the optimal process conditions to commercialize the pyrolysis technology. Pickering et al. (2000) highlighted this issue and conducted research on recovery of glass fibre from thermoset scrap composite materials using low a temperature combustion process. This study revealed that combustion might not be the appropriate technology as this process lost $(-50 \%)$ the tensile strength of fibre in comparison to virgin glass fibre which resulted to be fluffy, discontinuous and short in length. On the other hand, the pyrolysis process appeared as a very promising process for composite recycling. Table 2 lists the updated research on recovery of GFRC by showing operational parameters, mechanical properties using pyrolysis process. This process allows the re-use of all waste components and lead to recovery of valuable material and energy. Torres et al. (2000) used the pyrolysis process for testing sheet moulding compound of glass fibre and ortho-phthalic polyester in a lab scale fixed-bed reactor at $300-700^{\circ} \mathrm{C}$ for $30 \mathrm{~min}$. A considerable amount of organic solid material, gas and oil products were obtained from pyrolysis process. In a post-pyrolysis process, the solid char was burnt in an oxidation step and cleaned glass fibres were separated. The gas product mainly consisted of $\mathrm{CO}$ and $\mathrm{CO}_{2}$ and showed rather low gross calorific values of (13.9-16.4 MJ/ $\mathrm{Nm}^{3}$ ). The pyrolysis oils consisted mainly of majorly oxygenated and aromatic compounds. Cunliffe and Williams (2003) investigated the recycling of thermoset polyester/styrene copolymer reinforced with glass fibre in a pyrolysis process at $450{ }^{\circ} \mathrm{C}$. The main gases comprised of $\mathrm{H}_{2}, \mathrm{CH}_{4}, \mathrm{CO} \& \mathrm{CO}_{2}$ and oil contained $\mathrm{C}_{2}-\mathrm{C}_{4}$ hydrocarbons in high concentrations. The recovered fibres were successfully re-used in DMC (dough moulding compound) plaques and have mechanical properties comparable with virgin fibre. Another study by (Cunliffe et al., 2003) evaluated the recovery of a variety of composite wastes using a pyrolysis process in a bench scale reactor. The pyrolysis temperature was $350-800^{\circ} \mathrm{C}$ with a residence time of $60 \mathrm{~min}$ and a gas flow rate of $200 \mathrm{~cm}^{3} / \mathrm{min}$. A thermogravimetric analysis was conducted to study the Arrhensius kinetic parameters. However, the mechanical properties of reclaimed fibre were not presented. López et al. (2012) investigated recovery of GF and its re-utilization to synthesis glassceramic material. Pyrolysis of polyester fibreglass was performed in a $9.6 \mathrm{dm}^{3}$ thermolytic reactor at $550{ }^{\circ} \mathrm{C}$ for $3 \mathrm{~h}$. The pyrolysis process yielded an oil (24 wt\%), gas ( $8 \mathrm{wt} \%)$ and solid residue of ( $68 \mathrm{wt} \%)$. The long residence time in a slow pyrolysis may be responsible for the high solid content. Similar oil contents and gas components from slow pyrolysis are mentioned by (Torres et al., 2000) and (Cunliffe and Williams, 2003). The recovered glass fibre were processed to a vitrification process to prepare glass-ceramic tile. Recovery of GFRC using 

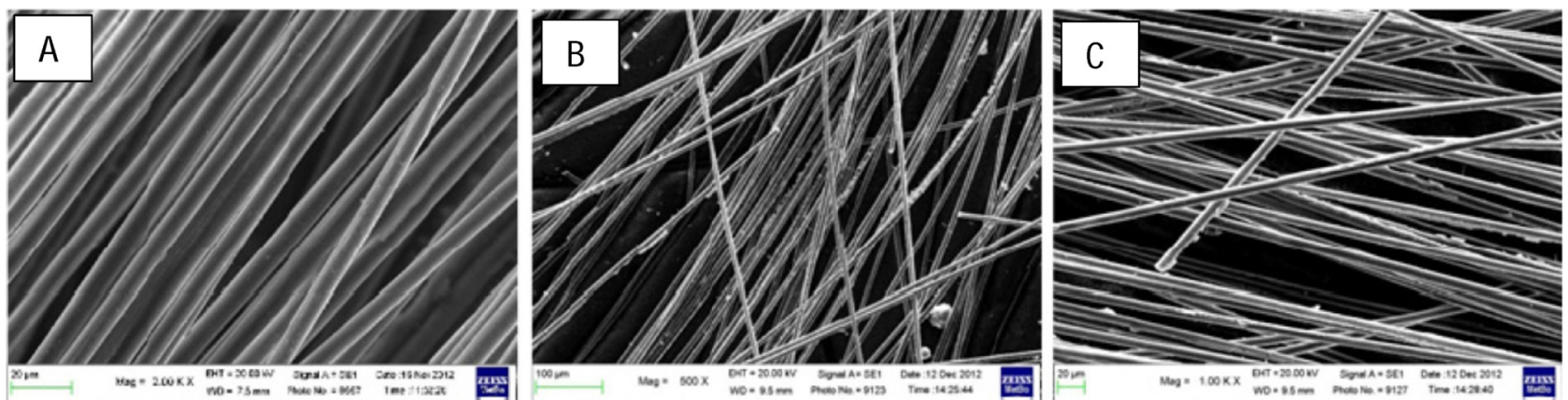

Fig. 6. SEM images of carbon fibres recovered from pyrolysis at (a) $500{ }^{\circ} \mathrm{C}$, (b) $550{ }^{\circ} \mathrm{C}$ and (c) $600{ }^{\circ} \mathrm{C}$ (Giorgini et al., 2014 ).

a pyrolysis process under non-isothermal and isothermal conditions were investigated by (Yun et al., 2014) and (Yun et al., 2015). In the first study, pyrolysis behaviour of composite scrap were determined under non-isothermal conditions at various heating rates and temperatures using a thermogravimetric analysis (TGA) and batch-type pyrolyzer. The kinetics of GFRC is calculated by following Arrhenius equation, ranging $41.4 \mathrm{~kJ} / \mathrm{mol}$ to $78 \mathrm{~kJ} / \mathrm{mol}$. The structure of GFRC is different in nature than biomass and cannot retain the structure under high temperature degradation. FT-IR and SEM analysis of GFRC char revealed that the structure is more stable at higher temperature and ash components tend to break on further heating. On the other hand, GFRC pyrolysis characteristics were evaluated at a temperature range of 500-1000 ${ }^{\circ} \mathrm{C}$ under isothermal conditions. At higher temperatures, the kinetic study showed a lower activation energy of $28.1 \mathrm{~kJ} / \mathrm{mol}$, preexponential factor $2.12 \mathrm{~s}^{-1}$ at the reaction order of $0.48-0.8$ in the thermos-balance reactor. This study also concluded that by increasing temperature and residence time, a polymer scission and re-polymerization phenomenon was observed. GFRC polyester resin laminates were pyrolysed in a batch pilot plant to investigate the effect of temperature on yields and chemical-physical properties of pyrolysis products (Giorgini et al., 2016). The products yield were: solid (40-45 wt$\%)$, gas (15-20 wt-\%) and oil (35-40 wt-\%) as a function of the pyrolysis temperature. To remove the carbonaceous residue and clean the fibre surface, post-pyrolysis experiments were conducted in a muffle furnace at 500 or $600{ }^{\circ} \mathrm{C}$ and kept isothermally at various residence times (10-60 min). This study also confirmed the presence of $\mathrm{CH}_{4}, \mathrm{H}_{2}$, $\mathrm{CO}$ and $\mathrm{CO}_{2}$ in high concentrations as the pyrolysis temperature increased. In pyrolysis oil, BTEX (benzene, toluene, ethylbenzene) is produced in large amounts at higher temperatures. A SEM analysis revealed that the thickness of the carbonaceous layer is reduced as the pyrolysis temperature increased. Raman spectroscopy results showed that by oxidation of char at $600{ }^{\circ} \mathrm{C}$, only $20 \mathrm{~min}$ is needed to completely remove the carbonaceous layer. In a recent study, recovery of glass fibre from thermoset composite is done by batch pyrolysis at $500{ }^{\circ} \mathrm{C}$ and 45 min residence time (Onwudili et al., 2016). The aim of this study was to exploit the impact of pyrolysis plus post-pyrolysis at a particular condition on recovery of material and compare the mechanical properties with virgin fibre and re-manufactured low density polyethylene composite (LDPEC). According to this study, better properties could be achieved not only through oxidation (post-pyrolysis) but also by chemical modification of fibre surface.

\subsection{Role of post-pyrolysis treatment in recovery}

As mentioned in the previous section, the pyrolysis process produces solid (char + fibre), gas and pyrolysis oil. The contaminated fibre surface with solid char is a problem for re-utilization. Low temperature combustion and gasification processes used large amount of hot air to remove the carbonaceous layer for separation of fibre. Post-pyrolysis treatment is mandatory to clean the fibre surface before re-combining the reclaimed fibre with thermoset or thermoplastic composites to synthesis new composite. This post treatment is done by an oxidation process in a controlled temperature and residence time. The optimization of process variables (temperature and residence time) is a key challenge in the post-pyrolysis process. The surface characteristics of recovered fibre was measured using X-ray photoelectron spectroscopy (XPS) (Jiang et al., 2008). The incorporation of carbonyl and carboxylic groups at the surface of the fibres might be due to the heat effect in the presence of air. Ultimately, surface properties may impact the interfacial bonding performance. A recent study investigated the structureproperty relationship of recycled fibres from the pyrolysis process (Jiang and Pickering, 2016). The oxidative effect (in air) and thermal effect (in nitrogen) were important parameters on influencing the surface properties. Surface defects were observed in an oxidative environment and caused reduction in tensile strength and crystallite size. Therefore, a controlled and optimized temperature and residence time in post-pyrolysis is beneficial for a viable recycling process.

\subsection{Gas and oil products}

Recycling of CFRC/GFRC using a pyrolysis process is promising as it can not only recover the valuable fibre material but also generate gaseous and oil products. The gas mixture by pyrolysis process could be measured using a gas analyser. According to the literature mentioned in the Tables 1 and 2, the major gas components are $\mathrm{H}_{2}, \mathrm{CH}_{4}, \mathrm{CO}$ and $\mathrm{CO}_{2}$ because of high secondary cracking. The amount of these gases mainly depends on the mode of pyrolysis (slow or fast), pyrolysis temperature and residence time. Furthermore, it is noticed that fraction of carbon oxides generated in larger concentration at higher temperature from the breakdown of oxygen-rich components presence in the resin formulation. The pyrolysis oil obtained from the pyrolysis of composite waste show a mainly aromatic nature. Benzene, toluene, ethyl benzene pXylene and styrene were identified through gas chromatography mass spectroscopy (GC-MS) as main components in the organic fraction. Besides aromatics, oxygenated species are also present in the pyrolysis oil. Fig. 7 summarizes the main gaseous and oil fractions.

\section{Characterization of recovered fibre using pyrolysis process}

To better understand the recycling process, characterization of the feedstock and recycled products provide key information about the thermo-chemical process. The details of these characterizations are not discussed here but their importance and impacts are highlighted. For thermal decomposition behaviour estimation, thermogravimetric analysis (TGA) was widely adopted (Bücheler et al., 2016). The curves of TG and DTG showed the mass loss of the resin with respect to temperature and the decomposition temperature of the resin and oxidation temperatures of the fibres. This would help to optimize the pyrolysis and post-pyrolysis process by avoiding the oxidation and degradation of the recovered fibres. According to published literature, in the case of GRFC, the decomposition temperature of the resin completed between $450-500{ }^{\circ} \mathrm{C}$ (Yun et al., 2014) and (Giorgini et al., 2016). On the other 


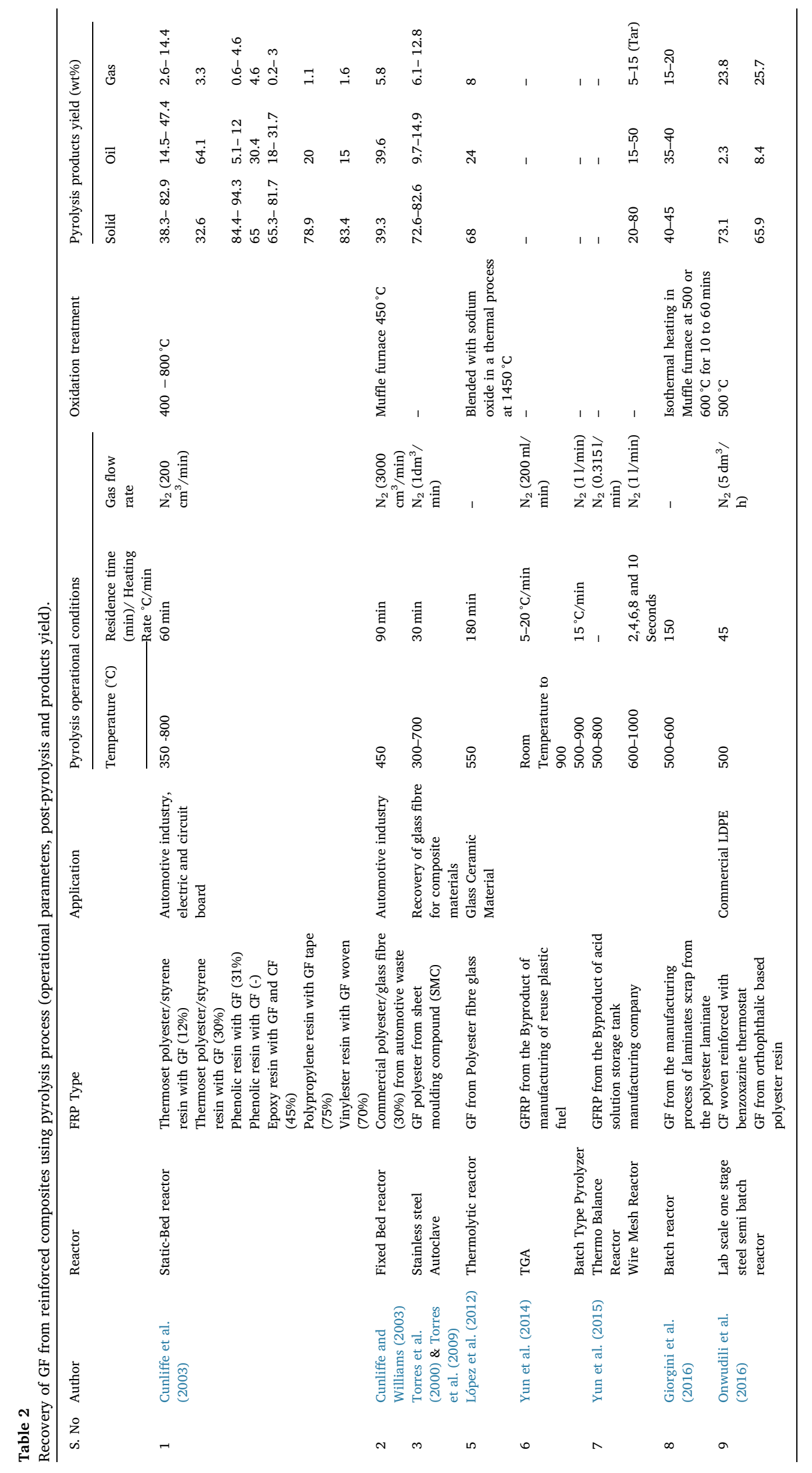




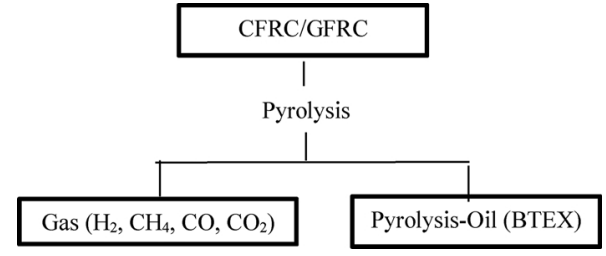

Fig. 7. Major Gas and oil components upon pyrolysis of CFRC/GFRC.

hand, CFRC showed decomposition range of $450-600^{\circ} \mathrm{C}$ depending on the cured \& uncured samples (Giorgini et al., 2015) and (Kim et al., 2017) for pyrolysis process. For post-pyrolysis in presence of air, $500-600{ }^{\circ} \mathrm{C}$ was identified as the appropriate temperature range for oxidation of pyrolytic char and clean the fibre surface (López et al., 2013) and (Kim et al., 2017). Attenuated total reflection coupled with Fourier-transform infrared spectroscopy (ATR-FTIR) showed up as a reliable tool for identification of functional groups present on recovered fibres in comparison to virgin material (Das and Varughese, 2016). The mechanical properties such as tensile strength (MPa), young modulus (MPa), flexural properties, elongation at break $(\mathrm{mm})$ along with diameter $(\mu \mathrm{m})$ and initial fibre length $(\mathrm{mm})$ were determined to exploit the effect of recycling process (Yildirir et al., 2015) and (Song et al., 2017). Morphological analyses of the recovered fibre were performed using SEM, Raman and XPS analysis. For other analyses such as length distribution and interfacial adhesion determination, image analysis for fibre length (Yang et al., 2012) and micro-bond test for interfacial adhesion between varying pyrolysis conditions for recovered fibre and polymer (Kim et al., 2017). Table 3 shows an overview of characterization techniques employed for investigation of fibre thermal, mechanical and morphological analyses.

The measurement of mechanical properties of recovered fibres (CF/ GF) heavily depends on the recycling options. Reclaimed fibres are fluffy in nature, non-aligned and discontinuous. Keeping in mind that scrap and recycled composites must have acceptable mechanical properties for the high value applications as well as for present approach. The mechanical properties are affected by poor adhesion of recycled fibre and epoxy resin. Pimenta and Pinho (2011), Asmatulu et al. (2014) and Oliveux et al. (2015) identified in their studies that pyrolysis is the only process who produces the better mechanical properties recycled fibres and has commercial-scale implementation in composite structures. To address the issues regarding mechanical properties, pyrolysis recycling option should be monitored through controlled temperature with fast heating rates, appropriate residence time and suitable length of raw material (Table 4).

In the light of literature, recovered GF does not allow a re-use for high value application because of the low market potential. Recovered CF which are intermingled like a tuft or hair, showed $5-10 \%$ loss in tensile strength using pyrolysis process as compared to combustion (18\%). However, more research work is required to understand the mechanisms involved.

In order to assess the opportunities to use recovered carbon fibres as a structural reinforcement in a circular economy, the source of material, cost savings lightweight material preparation with recovered fibres and large scale operation for high value applications for recovered carbon fibres in comparison to the virgin fibres are necessary to exploit. The recycled fibres produced at lower cost in comparison to virgin fibres but the nature of recycled fibres are inevitably different from virgin and this factor has limited the penetration/re-use of recovered fibre into virgin fibre market. Therefore, the challenge is to change the material in the form which replaces the virgin fibre with recycled fibre on the basis of cost and performance.

Carbon fibre composite materials upon pyrolysis can produce short, discontinuous and short in length fibres (Longana et al., 2016). However, these fibres possessed unique features such as cost effective lightweighting, 3D complex structure, panel shape through compression moulding and secondary structure for aircraft interior (Oliveux et al., 2015). In terms of properties, recycled fibres showed promising mechanical properties in comparison with virgin fibres using the thermochemical conversion process. Using pyrolysis process, fibres strength slightly reduced $(\sim 10 \%)$, in comparison to combustion process which showed more loss in strength ( $\sim 50 \%)$ (Wong et al., 2017). Recycled fibre upon pyrolysis showed similar electrical conductivity to that of virgin fibre (Overcash et al., 2018). In terms of structure-property relation after recovery using pyrolysis process, oxygenated species are still active on the surface and fibres have been found bond well to epoxy resin (Jiang and Pickering, 2016).

In terms of performance, re-manufacturing of composite structures strongly depend on fibre reclamation process. Through direct or injection moulding technique, mixture of resin and recovered fibre (short, discontinuous, chopped and milled) is pre-compounded into pellets. ELG Carbon fibre, UK used produce milled fibre to produce nonwoven mats for lightweight composite production (Holmes, 2017). In automotive application, recycled carbon fibres products offer lighter and stiffer parts at high volume manufacturing rates and significant cost savings (Meng et al., 2018). For complex shape parts and panel shapes, discontinuous and shorter length fibres seem to product high quality 3D complex and lightweight structure. Recently, GE introduced jet engine bracket challenge to optimize highly efficient bracket structure. The recycled 3D random, disoriented fibres have potential to be part of optimized lightweight bracket design (Gebisa and Lemu, 2017). There are many other potential applications for recycled fibres to be used as structural reinforcement composites with wide range of properties. Below are several approaches for re-use;

1 Competition with virgin materials (composite/metallic)

2 Low mechanical performance may be offset by low cost

3 The scale should be identified for comparison of recycled material to other material such as tow, mat or compound

4 Penetration into new markets

5 Appropriate use of recycled fibres to form new materials

6 Replacement of glass fibre as well as virgin carbon fibres with recycled carbon fibres.

7 Enlarge functionality

8 Exploiting the utilization of recycled fibres in applications where vital properties is of least importance

9 3D orientation, discontinuous and uniform fibre may be used in applications to give enhanced drape properties for automated forming

10 Down-cycling of carbon fibre, where might be it is preferred for least demand application.

Currently many routes for market development are under

Table 3

Overview of characterization techniques involved in the FRC recycling processes.

\begin{tabular}{|c|c|c|c|}
\hline Thermal \& functional group Analysis & Mechanical Testing & Morphological Testing & Others \\
\hline $\begin{array}{l}\text { TGA }\left(\mathrm{N}_{2}\right) \text {-PyrolysisTGA (Air)-Post- } \\
\text { pyrolysis }\end{array}$ & $\begin{array}{l}\text { Tensile Properties -tensile strength (MPa), -Young modulus } \\
\text { (MPa), -Elongation at break (\%) }\end{array}$ & SEM, AFM & $\begin{array}{l}\text { Adhesion analysis -Micro bond test, } \\
\text {-fibre pull out }\end{array}$ \\
\hline ATR-FTIR & & $\begin{array}{l}\text { XPS \& Raman for surface } \\
\text { analysis }\end{array}$ & $\begin{array}{l}\text { Image analysis for fibre length } \\
\text { distribution }\end{array}$ \\
\hline
\end{tabular}


Table 4

Mechanical properties of single recovered fibre from pyrolysis of CFRC/GFRC.

\begin{tabular}{|c|c|c|c|c|c|c|c|}
\hline \multirow[b]{2}{*}{ References } & \multirow[b]{2}{*}{ Output } & \multicolumn{6}{|c|}{ Properties of single recovered fibre from pyrolysis process } \\
\hline & & Tensile strength (MPa) & Stiffness \& purity & Young modulus (MPa) & Elongation at break, (\%) & Diameter & Fibre length (mm) \\
\hline \multirow[t]{2}{*}{ Nahil and Williams (2011) } & $\mathrm{CF}$ & $2340-3270$ & - & $230-233$ & $2.34-3.27$ & - & - \\
\hline & & $910-1250$ & - & $182-233$ & $0.91-1.25$ & - & - \\
\hline Greco et al. (2013) & $\mathrm{CF}$ & & $14 \%$ reduction & $8 \%$ reduction & - & 6.2 & \\
\hline Stoeffler et al. (2013) & $\mathrm{CF}$ & $680-720 \%$ increase & & $680 \%$ increase & $20-35 \%$ increase & 6.5 & 5.6 \\
\hline López et al. (2013) & $\mathrm{CF}$ & $2537-2544$ & - & $210-220$ & - & $6.70-7.00$ & - \\
\hline Giorgini et al. (2016) & GF & 14 & - & 530 & - & - & - \\
\hline Onwudili et al. (2016) & $\mathrm{GF}$ & 11 & - & 428 & - & - & - \\
\hline
\end{tabular}

consideration and the outlook is debatable. Recycled carbon fibre nonwoven mats, recycled carbon fibres comingled with thermoplastic fibres, chopped, tow and milled fibre are potential avenues. In a circular economy, carbon fibres resources are kept in use for as long as possible with maximum recovery, re-use for new composites and promising material for viable applications at the end of service life.

\section{Re-use of fibre}

The key driving force for recycled fibres in a circular system would be fibre reclaiming process who can provide good quality fibre to prepare new composite for an end user application or intermediate product manufacturer. A high value end user application empower a viable supply chain for recovered fibre than a low value. Nonwoven mats with 3D complex shape and discontinuous fibre permit remarkable mechanical properties to be achieved through high fibre volume fraction in composite limited fibre breakage during moulding. Recycled carbons fibres might cannot compete with virgin carbon fibres in terms of performance but it would be viable in terms of weight-savings, cost, synthesis of complex shape which is acceptable for specific automotive and parts industries in a circular system. The effective recovery method which can produce good quality fibres at mild conditions and their reuse for new composite is still a part of on-going research. Pyrolysis process produce short, discontinuous, fluffy fibres which went through various process. These re-manufacturing processes are introduced by (Pimenta and Pinho, 2011). Their study explained re-manufacturing processes: such as direct moulding, compression moulding of nonwoven and aligned mats and impregnation of woven mats techniques by showing advantages, disadvantages and implementation. This re-use mainly depends on the physical structure and mechanical properties of the recycled fibres. Further technical advancement in terms of fibre alignment, increasing fibre content and reduction in fibre breakage during processing are still needed. A suitable, effective and low cost fibre recovery process in combination with suitable re-manufacturing process should be developed to reach the properties and performance of virgin fibres. This recycled discontinuous, 3D oriented fibre have ability to manufacture few structure components as technology demonstrators: secondary components for the automotive industry, interior components of the aircraft and tooling. In general, recovered fibres after removal of residual char clean, showed acceptable mechanical properties in comparison to virgin material, especially in case of recovered $\mathrm{CF}$ (Giorgini et al., 2015).

An example of CFRC recovery using pyrolysis process following a reformulation of new composite in combination with reclaimed fibres is depicted in Fig. 8. However, further technical developments in remanufacturing processes are needed, especially in fibre alignment, fibre content in new composite and low fibre damage during synthesis process. In a nutshell, an efficient recycling process is heavily influenced by the mechanical properties of recovered fibres which will be re-processed with the polymer to prepare a suitable composite with properties comparable to virgin CFRC.

\section{Gaps in research and development and recommendations}

In this section, the research gaps are discussed by summarizing and presenting the present research work on recycling of CFRC/GFRC using the promising route, pyrolysis, for a sustainable circular economy. The pyrolysis process is identified as the most viable and sustainable process to conserve the resources and to provide efficient recycling by the following cradle-to-cradle approach. Based on the literature, the production of composite scrap, technical aspects of pyrolysis process and its effect on recovered material properties, pyrolysis products and re-use of reclaimed fibre in a closed life cycle are summarized and described. However, a number of research questions can be derived from the present study. Further developments in pyrolysis process for recovery of $\mathrm{CF} / \mathrm{GF}$ can be planned and solved through the following identified research gaps and further prospects:

1 CFRC scrap is available in cured and uncured thermoset matrices form in an industrial scale. There is still much work needed by evaluating the effect of the stepwise pyrolysis process. Such an evaluation should reveal the relationship between the parameters of the pyrolysis process of cured and uncured CFRC and the properties of the recovered fibres and produced chemicals \& fuels.

2 What is the performance of a pyrolysis process for mixed and contaminated wastes in a suitable experimental facility? Most of the work presented in literature is performed on a muffle furnace or a fixed-bed reactor. A fluidized-bed reactor or spouted bed reactor or any other reactor with the ability to process mixed and contaminated wastes are not addressed yet.

3 To better understand the impact of the pyrolysis recycling process, the optimized process parameters for both the pyrolysis and postpyrolysis are required. A single set of conditions were used by researchers. Research on the optimized process parameters for pyrolysis recycling process is also crucial for further improvement of the quality of the recovered fibres.

4 An economic and energy analysis of CFRC recycling using a low temperature fluidized bed combustion process by using Fluidizedbed process is recently reported (Meng et al., 2017). However, a detailed investigation of an economic and energy analysis of pyrolysis process is missing in literature. This information will demonstrate the environmental benefits of recycled fibres, especially in case of CFRC, against end-of-life landfilling. A mathematical model available could be developed to illustrate the influence of pyrolysis and post-pyrolysis processing variations and other relevant factors on cost and environmental impact.

5 The effect of fibre reclamation on composite performance in comparison to virgin and recycled composite with identical structures are not clear.

6 How can the initial fibre length and strength be retained after recovery via pyrolysis. The longer the initial fibre length, the longer the recovered fibre length but the understanding of thermal and oxidation treatment impact is required for further quality improvement and cost reduction of the products. 


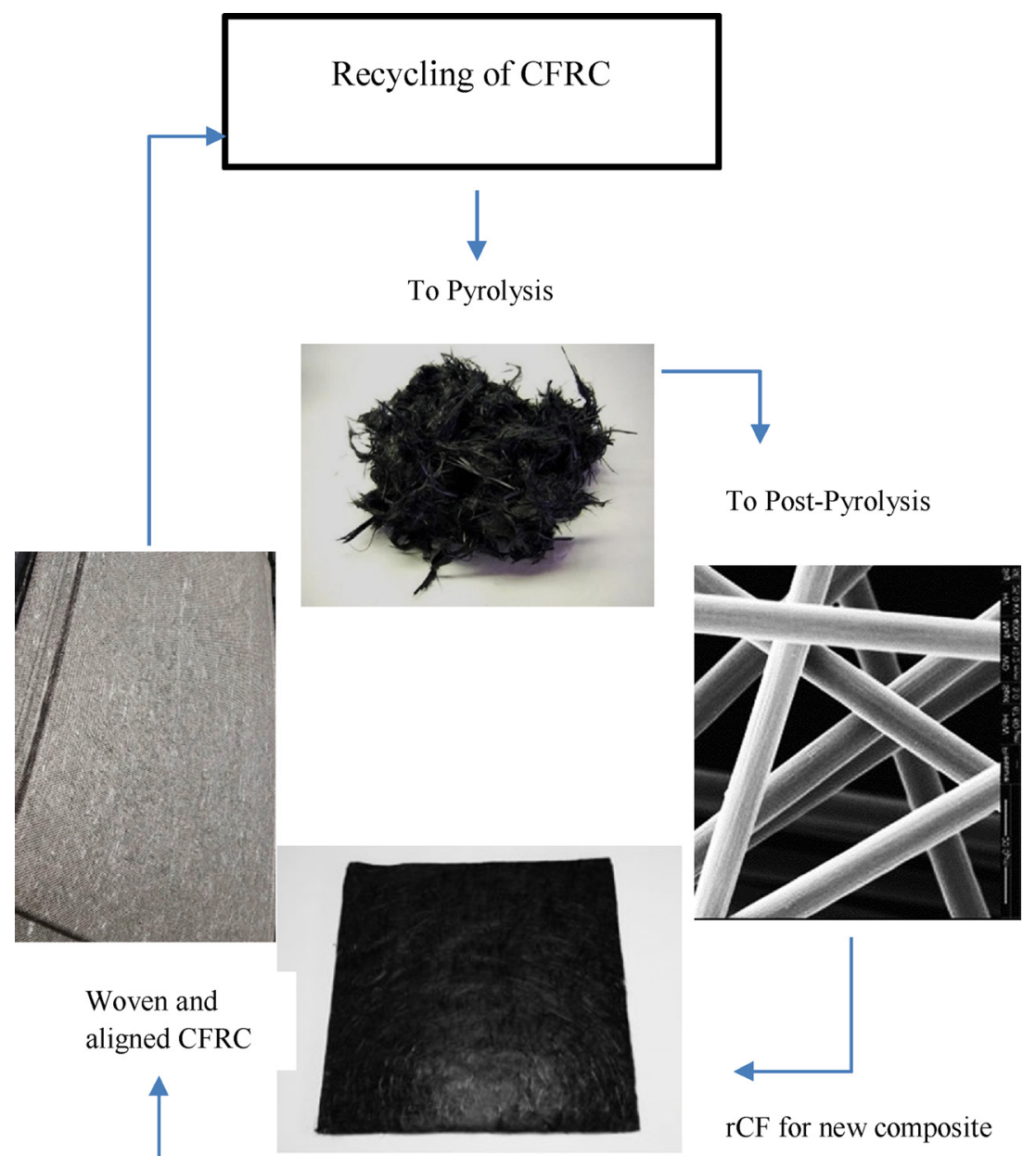

Fig. 8. Closed life cycle for CFRC in a circular economy.

7 According to literature, the mechanical properties of recovered fibres via pyrolysis showed a better performance as compared to combustion and gasification treatment, mechanical and chemical methods. However, these properties are negatively influenced by an-appropriate set of conditions of the pyrolysis process (e.g. low heating rates and long residence time). To re-use the recovered fibres for a high-grade composite application, this compromise will not be tolerated.

8 Commercially, no products are made from discontinuous, fluffy and non-aligned recovered fibres via pyrolysis are available yet. More research application of recovered fibres is required.

9 Another important issue for research is the absence of sizing on the recycled fibre surface. This may lead to poor adhesion between the polymer resin and recovered fibres, which will result in poor mechanical properties. A specific re-sizing of reclaimed fibres via pyrolysis would show significant improvement in mechanical properties.

10 There is no information regarding fibre grading and fractioning in literature to eliminate the short fibres and maintain high purity \& strength with no loss of fibre volume fraction in the recycled composite via pyrolysis.

11 Hybridization or replacement of recovered glass fibre (rGF)/ virgin carbon fibre (vCF) with recovered carbon fibre (rCF) from the pyrolysis process for new composites is not suggested before. This replenish will develop new high quality materials.

\section{Acknowledgment}

This work is funded by Science Based Engineering Program of the University of Twente, Netherlands.

\section{References}

Abdou, T.R., et al., 2016. Recovering of carbon fiber present in an industrial polymeric composite waste through pyrolysis method while studying the influence of resin impregnation process: prepreg. REWAS 2016. In: Kirchain, R.E., Blanpain, B., Meskers, C. (Eds.), Towards Materials Resource Sustainability. Springer International Publishing, Cham, pp. 313-318.

Akanbi, L.A., et al., 2018. Salvaging building materials in a circular economy: a BIMbased whole-life performance estimator. Resour. Conserv. Recycl. 129 (Supplement C), $175-186$

Asmatulu, E., et al., 2014. Recycling of fiber-reinforced composites and direct structural composite recycling concept. J. Compos. Mater. 48 (5), 593-608.

Bhadra, J., et al., 2017. 11 - Recycling of polymer-polymer composites A2 - Mishra, Raghvendra Kumar. In: Thomas, S., Kalarikkal, N. (Eds.), Micro and Nano Fibrillar Composites (MFCs and NFCs) from Polymer Blends. Woodhead Publishing, pp. 263-277.

Bradna, P., Zima, J., 1992. Compositional analysis of epoxy matrices of carbon-fibre composites by pyrolysis—gas chromatography/mass spectrometry. J. Anal. Appl. Pyrolysis 24 (1), 75-85.

Bücheler, D., et al., 2016. Using thermogravimetric analysis to determine carbon fiber weight percentage of fiber-reinforced plastics. Compos. Part B-Eng. 106 (Supplement C), 218-223.

Cunliffe, A.M., et al., 2003. Recycling of fibre-reinforced polymeric waste by pyrolysis: thermo-gravimetric and bench-scale investigations. J. Anal. Appl. Pyrolysis 70 (2), 315-338.

Cunliffe, A.M., Williams, P.T., 2003. Characterisation of products from the recycling of glass fibre reinforced polyester waste by pyrolysis 攵. Fuel 82 (18), 2223-2230.

Das, M., Varughese, S., 2016. A novel sonochemical approach for enhanced recovery of carbon fiber from CFRP waste using mild acid-peroxide mixture. ACS Sustain. Chem. Eng. 4 (4), 2080-2087. 
Das, P., Tiwari, P., 2018. Valorization of packaging plastic waste by slow pyrolysis. Resour. Conserv. Recycl. 128 (Supplement C), 69-77.

Erden, S., Ho, K., 2017. 3 - Fiber Reinforced Composites. Fiber Technology for FiberReinforced Composites. Woodhead Publishing, pp. 51-79.

Gebisa, A.W., Lemu, H.G., 2017. A case study on topology optimized design for additive manufacturing. IOP Conference Series: Materials Science and Engineering.

Giorgini, L., et al., 2015. Recovery of carbon fibers from cured and uncured carbon fiber reinforced composites wastes and their use as feedstock for a new composite production. Polym. Compos. 36 (6), 1084-1095.

Giorgini, L., et al., 2014. Pyrolysis as a way to close a CFRC life cycle: carbon fibers recovery and their use as feedstock for a new composite production. AIP Conf. Proc. 1599 (1), 354-357.

Giorgini, L., et al., 2016. Pyrolysis of fiberglass/polyester composites: recovery and characterization of obtained products. FME Transactions 44 (4), 405-414.

Greco, A., et al., 2013. Thermal and chemical treatments of recycled carbon fibres for improved adhesion to polymeric matrix. J. Compos. Mater. 47 (3), 369-377.

Habib Al Razi, K.M., 2016. Resourceful recycling process of waste desktop computers: a review study. Resour. Conserv. Recycl. 110 (Supplement C), 30-47.

Holgersson, S., et al., 2017. Analysis of the metal content of small-size Waste Electric and Electronic Equipment (WEEE) printed circuit boards_-part 1: internet routers, mobile phones and smartphones. Resour. Conserv. Recycl.

Holmes, M., 2017. Recycled carbon fiber composites become a reality. Rein. Plast. http:// dx.doi.org/10.1016/j.repl.2017.11.012.

Hoogmartens, R., et al., 2018. A hotelling model for the circular economy including recycling, substitution and waste accumulation. Resour. Conserv. Recycl. 128, 98-109.

Jiang, G., Pickering, S.J., 2016. Structure-property relationship of recycled carbon fibres revealed by pyrolysis recycling process. J. Mater. Sci. 51 (4), 1949-1958.

Jiang, G., et al., 2008. Surface characterisation of carbon fibre recycled using fluidised bed. Appl. Surf. Sci. 254 (9), 2588-2593.

Kim, K.-W., et al., 2017. Recycling and characterization of carbon fibers from carbon fiber reinforced epoxy matrix composites by a novel super-heated-steam method. J. Environ. Manage. 203 (Part 3), 872-879.

Kirchherr, J., et al., 2017. Conceptualizing the circular economy: an analysis of 114 definitions. Resour. Conserv. Recycl. 127, 221-232.

Lefeuvre, A., et al., 2017. Anticipating in-use stocks of carbon fiber reinforced polymers and related waste flows generated by the commercial aeronautical sector until 2050. Resour. Conserv. Recycl. 125 (Supplement C), 264-272.

Liu, Y., et al., 2017. A review of optimisation techniques used in the composite recycling area: state-of-the-art and steps towards a research agenda. J. Clean. Prod. 140 (Part 3), 1775-1781.

Longana, M.L., et al., 2016. Multiple closed loop recycling of carbon fibre composites with the HiPerDiF (High performance discontinuous fibre) method. Compos. Struct. 153, 271-277.

López, F.A., et al., 2012. Thermolysis of fibreglass polyester composite and reutilisation of the glass fibre residue to obtain a glass-ceramic material. J. Anal. Appl. Pyrolysis 93 (Supplement C), 104-112.

López, F.A., et al., 2013. Recovery of carbon fibres by the thermolysis and gasification of waste prepreg. J. Anal. Appl. Pyrolysis 104 (Supplement C), 675-683.

Louwes, A.C., et al., 2017. Torrefied biomass as feed for fast pyrolysis: an experimental study and chain analysis. Biomass Bioenergy 105 (Supplement C), 116-126.

Meng, F., et al., 2018. An assessment of financial viability of recycled carbon fibre in automotive applications. Compos. Part A: Appl. Sci. Manuf. 109, 207-220.

Meng, F., et al., 2017. Energy and environmental assessment and reuse of fluidised bed recycled carbon fibres. Compos. Part A: Appl. Sci. Manuf. 100, 206-214.

Meyer, L.O., et al., 2009. CFRP-Recycling following a pyrolysis route: process optimization and potentials. J. Compos. Mater. 43 (9), 1121-1132.

Nahil, M.A., Williams, P.T., 2011. Recycling of carbon fibre reinforced polymeric waste for the production of activated carbon fibres. J. Anal. Appl. Pyrolysis 91 (1), 67-75.

Naqvi, S.R., et al., 2018. Potential of biomass for bioenergy in Pakistan based on present case and future perspectives. Renew. Sustain. Energy Rev. 81 (Part 1), 1247-1258.

Oliveux, G., et al., 2015. Current status of recycling of fibre reinforced polymers: review of technologies, reuse and resulting properties. Prog. Mater Sci. 72 (Supplement C), 61-99.

Onwudili, J.A., et al., 2016. Recovery of glass fibre and carbon fibres from reinforced thermosets by batch pyrolysis and investigation of fibre re-using as reinforcement in LDPE matrix. Compos. Part B-Eng. 91 (Supplement C), 154-161.

Overcash, M., et al., 2018. Thermoset composite recycling - driving forces, development, and evolution of new opportunities. J. Compos. Mater. 52 (8), 1033-1043.

Pickering, S.J., 2006. Recycling technologies for thermoset composite materials-current status. Compos. Part. A: Appl. Sci. Manuf. 37 (8), 1206-1215.

Pickering, S.J., et al., 2000. A fluidised-bed process for the recovery of glass fibres from scrap thermoset composites. Compos. Sci. Technol. 60 (4), 509-523.

Pickering, S.J., Turner, T.A., 2014. Research and development in support of carbon fibre recycling. CAMX 2014 - Composites and Advanced Materials Expo: Combined Strength. Unsurpassed Innovation.

Pimenta, S., Pinho, S.T., 2011. Recycling carbon fibre reinforced polymers for structural applications: technology review and market outlook. Waste Manage. 31 (2), 378-392.

Poulikakos, L.D., et al., 2017. Harvesting the unexplored potential of European waste materials for road construction. Resour. Conserv. Recycl. 116 (Supplement C), 32-44.

Ribeiro, M.C.S., et al., 2015. Re-use assessment of thermoset composite wastes as aggregate and filler replacement for concrete-polymer composite materials: a case study regarding GFRP pultrusion wastes. Resour. Conserv. Recycl. 104 (Part B), 417-426.

Rybicka, J., et al., 2016. Technology readiness level assessment of composites recycling technologies. J. Clean. Prod. 112 (Part 1), 1001-1012.

Song, C., et al., 2017. Recycling carbon fiber from composite waste and its reinforcing effect on polyvinylidene fluoride composite: mechanical, morphology, and interface properties. Polym. Compos. 38 (11), 2544-2552.

Stoeffler, K., et al., 2013. Polyphenylene sulfide (PPS) composites reinforced with recycled carbon fiber. Compos. Sci. Technol. 84 (Supplement C), 65-71.

Torres, A., et al., 2009. Recycling of the solid residue obtained from the pyrolysis of fiberglass polyester sheet molding compound. Adv. Polym. Tech. 28 (2), 141-149.

Torres, A., et al., 2000. Recycling by pyrolysis of thermoset composites: characteristics of the liquid and gaseous fuels obtained. Fuel 79 (8), 897-902.

Vieira, D.R., et al., 2017. Strategy and management for the recycling of carbon fiberreinforced polymers (CFRPs) in the aircraft industry: a critical review. Int. J. Sustain. Dev. World Ecol. 24 (3), 214-223.

Witik, R.A., et al., 2013. Carbon fibre reinforced composite waste: an environmental assessment of recycling, energy recovery and landfilling. Compos. Part. A: Appl. Sci. Manuf. 49 (Supplement C), 89-99.

Wong, K., et al., 2017. Composites recycling solutions for the aviation industry. Sci. China Technol. Sci. 60 (9), 1291-1300.

Yang, Y., et al., 2012. Recycling of composite materials. Chem. Eng. Process.: Process Intensif. 51 (Supplement C), 53-68.

Yazdanbakhsh, A., et al., 2018. Concrete with discrete slender elements from mechanically recycled wind turbine blades. Resour. Conserv. Recycl. 128 (Supplement C), $11-21$.

Yildirir, E., et al., 2015. Evaluating the mechanical properties of reinforced LDPE composites made with carbon fibres recovered via solvothermal processing. Compos. Part B-Eng. 78 (Supplement C), 393-400.

Yu, K., et al., 2016. Carbon fiber reinforced thermoset composite with near 100\% recyclability. Adv. Funct. Mater. 26 (33), 6098-6106.

Yun, Y.M., et al., 2014. Pyrolysis characteristics of GFRP (glass fiber reinforced plastic) under non-isothermal conditions. Fuel 137 (Supplement C), 321-327.

Yun, Y.M., et al., 2015. Pyrolysis characteristics of glass fiber-reinforced plastic (GFRP) under isothermal conditions. J. Anal. Appl. Pyrolysis 114 (Supplement C), 40-46.

Zheng, Y., et al., 2009. A novel approach to recycling of glass fibers from nonmetal materials of waste printed circuit boards. J. Hazard. Mater. 170 (2), 978-982.

Zhong, S., Pearce, J.M., 2018. Tightening the loop on the circular economy: coupled distributed recycling and manufacturing with recyclebot and RepRap 3-D printing. Resour. Conserv. Recycl. 128, 48-58. 